\title{
Robust Coordinated Design of Power System Stabilizer and Excitation System Using Genetic Algorithm to Enhance the Dynamic Stability of Al-Zara Thermal Power Station Generation in Syria
}

\author{
Riad Al-Mustfa ${ }^{1}$, Anas Fattouh ${ }^{2}$ and Wassan A. Hashim ${ }^{3}$ \\ ${ }^{1,3}$ Power Systems Dept., Faculty of Electrical \& Electronic Engineering, \\ Aleppo University, Aleppo, Syria, and \\ ${ }^{2}$ Computer Science Dept., Faculty of Computing and Information \\ Technology, King Abdulaziz University, Jeddah, Saudi Arabia \\ ${ }^{1}$ riadmust@hotmail.com, ${ }^{2}$ afattouh@kau.edu.sa, \\ 3wassnaldoory@yahoo.com
}

\begin{abstract}
In this paper, a new formula of Power System Stabilizer (PSS) was adopted. The design of PSS and Excitation system (an Exciter) parameters is formulated as an optimization problem. A continuous genetic algorithm (GA) is employed for searching optimized parameters. A multi-objective function includes the deviation in the oscillatory rotor speed of the generator is minimized in time-domain to improve the stability performance of the system. The design is performed using linearized models of a real thermal power system, Al-Zara Thermal Power Station in Syria, at four operating conditions and large perturbation. A cubic Hermite interpolation technique is employed to determine the smoothest possible curve that passes through its data set obtained by the GA. The effectiveness and robustness of the designed stabilizer is investigated and compared with conventional PSS. The simulation results show that the GA stabilizer (GAPSS + GAExciter) are able to provide better damping over a wide operating range with large perturbation and improve the overall systems' performance.
\end{abstract}

Keywords: Power System Stability (PSS); Synchronous Generator; Excitation System; Genetic Algorithm; Cubic Hermite Interpolation. 


\section{Introduction}

Power system control requires a continuous balance between electrical generation and a varying load demand, while maintaining system frequency and voltage levels. The use of high performance excitation systems is essential for maintaining steady state and transient stability of modern synchronous generators and provides fast control of the terminal voltage. However, these fast acting exciters with high gains can contribute to oscillatory instabilities in the power system. These types of instabilities are characterized by low frequency oscillations which can persist or even grow in magnitude ${ }^{[1,2]}$. A cost efficient and satisfactory solution to this problem of low frequency oscillations is to provide damping system by implementing Power System Stabilizers (PSS), which are supplementary controllers in the generator excitation system ${ }^{[3]}$. The problem of PSS is the parameter tuning which is done by trial and error and therefore makes it an inrobust system and is very time consuming and requires a lot of effort.

A number of conventional techniques have been reported in the literature pertaining to design problems of conventional power system stabilizers namely: The eigenvalue assignment, mathematical programming, and gradient procedure. Unfortunately, the conventional techniques are time consuming as they are iterative and require heavy computation burden and slow convergence. In addition, the search process is susceptible to be trapped in local minima and the solution obtained may not be optimal ${ }^{[4,5]}$.

In recent years, several approaches based on modern control theory have been applied to PSS design problem. These include optimal control, adaptive control, variable structure control and intelligent control.

Despite the potential of modern control techniques, power system utilities still prefer the conventional lead lag PSS structure. The parameters of CPSS are based on a linearized model of the power system. Since modern power systems are dynamic and non linear in nature, CPSS performance is degraded whenever the operating point changes from one point to another because of the fixed parameters of the stabilizer ${ }^{[6]}$.

Due to the fast development of intelligent techniques applications in power systems during this decade, many researchers in the field of power systems have paid more attention to applications of such 
techniques to solve power system problems ${ }^{[7-10]}$. In order to make the design simpler, genetic algorithm GA has been successfully applied to PSS design ${ }^{[11,12]}$.

GA is defined as a global optimization technique based on the mechanics of natural selection and survival-of-the-fittest, and it can be applied directly to various problems, without the need to transform them into mathematical formulations ${ }^{[13,14]}$. High and rapid convergence, low computer burden and avoiding local minima are the main features of this technique.

The Main Objectives of this work are summarized as follows:

- To present a systematic approach for the design of proposed PSS and Excitation system for stability enhancement of power system using GA (called GAPSS).

- To study the dynamic performance of the system, a practical case study on the dynamic stability of the Al-Zara Thermal Power Station (ZTPS) under wide range of loading conditions and also tested under large perturbations (3-phase fault) using Matlab $^{\circledR} /$ Simulink $^{\circledR}$.

- To compare the performance of the GAPSS with the conventionally tuned PSS.

- To study the piecewise cubic Hermite interpolation that is used to fit a smooth continuous function through the obtained list of PSS and Excitation parameters.

- To investigate the effectiveness and robustness of the PSS and Excitation system in both cases GA and interpolation under the wide variations of loading conditions.

\section{System Modeling}

Al-Zara Thermal Power Station (ZTPS), a Syrian thermal power station, is considered here as a practical case study. It includes the following components: the nonlinear machine model with a 2-axis representation of the generator, the excitation system type MEC-5310T, and conventional lead/lag Power System Stabilizer (CPSS $)^{[11]}$. The diagram of power system ZTPS is shown in Fig. 1.

The equations of each part in the model are derived in the following: 


\section{1) Synchronous Generator Model}

The synchronous generator of ZTPS is represented by sixth-order model given in the following equations where the variables are defined in Appendix 1.

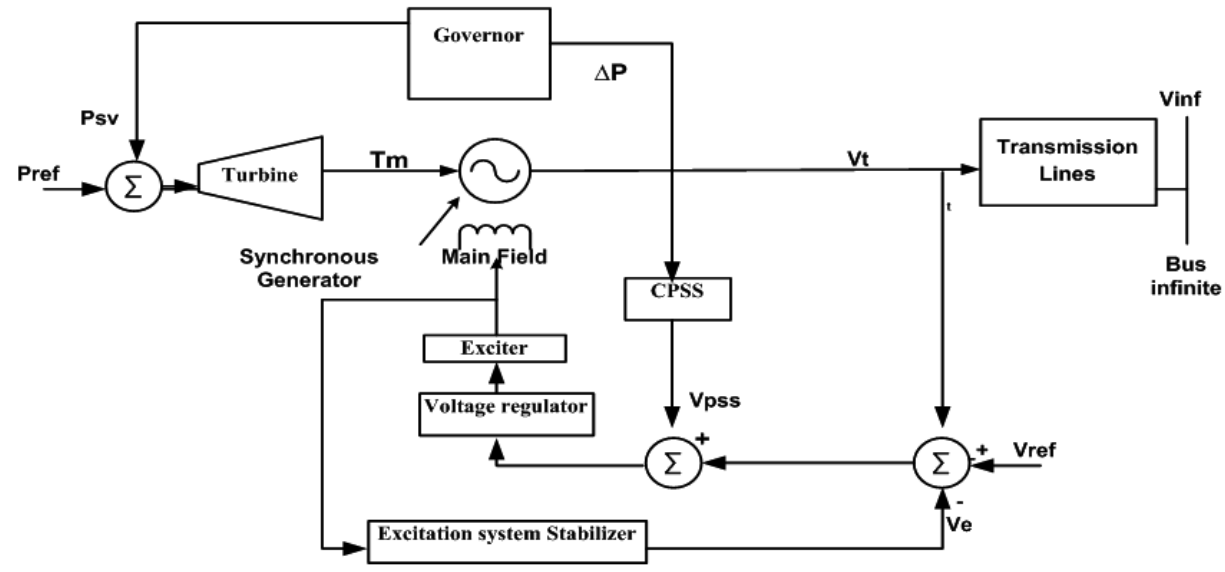

Fig. 1(a). Block diagram of Al-Zara Thermal Power System (ZTPS).

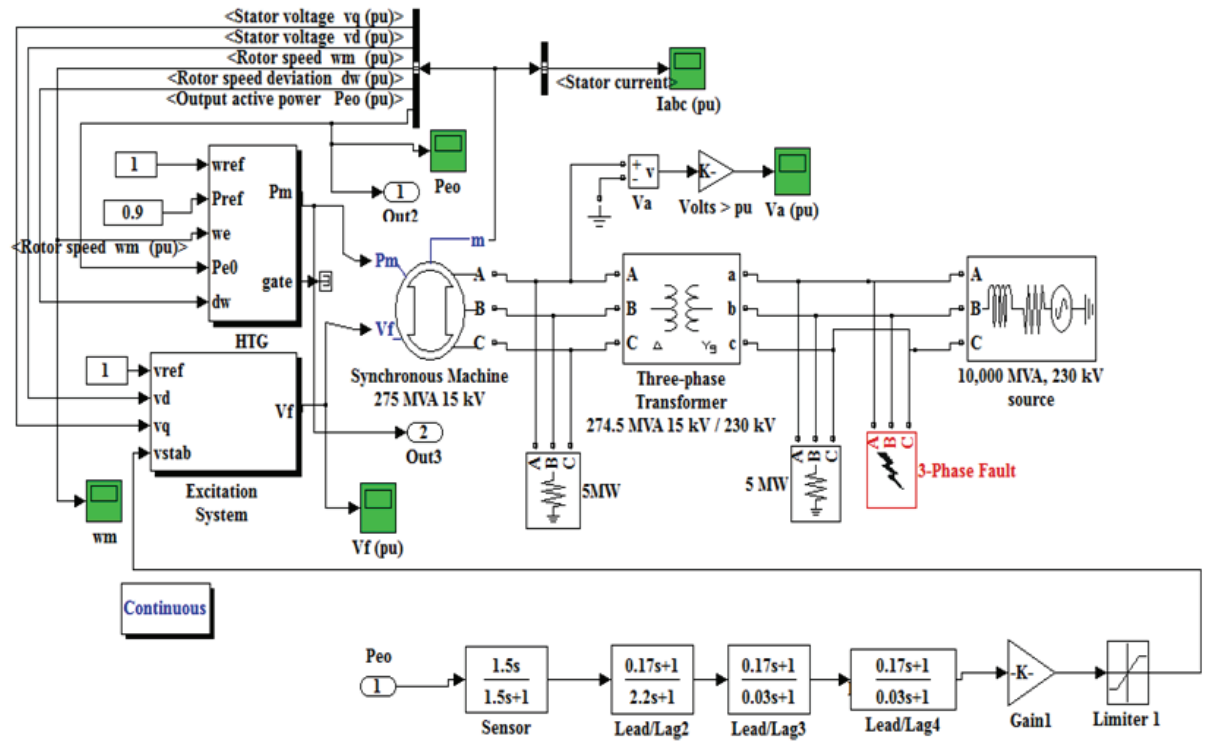

Fig. 1(b). Model of ZTPS in Matlab/Simulink.

$$
\begin{gathered}
2 H \Delta \dot{\omega}=P_{m}-P_{e} \\
\dot{\delta}=\Delta \omega
\end{gathered}
$$




$$
\begin{gathered}
T_{d o}^{\prime} \dot{V}_{q}^{\prime}=E_{f}-V_{q}^{\prime}+I_{d}\left(X_{d}-X_{d}^{\prime}\right) \\
T_{q o}^{\prime} \dot{V}_{d}^{\prime}=-V_{d}^{\prime}-I_{q}\left(X_{q}-X_{q}^{\prime}\right) \\
T_{d o}^{\prime \prime} \dot{V}_{q}^{\prime \prime}=V_{q}^{\prime}-V_{q}^{\prime \prime}+I_{d}\left(X_{d}^{\prime}-X_{d}^{\prime \prime}\right) \\
T_{q o}^{\prime \prime} \dot{V}_{d}^{\prime \prime}=V_{d}^{\prime}-V_{d}^{\prime \prime}-I_{q}\left(X_{q}^{\prime}-X_{q}^{\prime \prime}\right)
\end{gathered}
$$

\section{2) The Excitation System}

Exciters are used to provide direct current to the synchronous machine field winding. In addition, they allow the operator to control the reactive power injected in the power system by controlling the field current. An excitation-control system employs a voltage controller to control the excitation regulator (AVR). Excitation system control is accomplished by control of thyristor power amplifier, and the various systems generally can be divided into one of the following types ${ }^{[2,3]}$ :

a. Static exciters: operate directly on the field of an AC generator.

b. Voltage regulator: usually controls the field of an auxiliary machine (exciter), whose output is either rectified or directly connected to the AC generator.

The excitation system can be controlled automatically by means of a digital regulator system or manually with an analog backup system ${ }^{[15,16]}$.

The excitation system type MEC-5310T is used in this real practical model of Al-Zara Thermal Power Station and it is depicted in Fig. $2^{[17]}$. Notice that the switches in Fig. 2 are used to connect a Torsional filter to compensate high frequencies in the field.

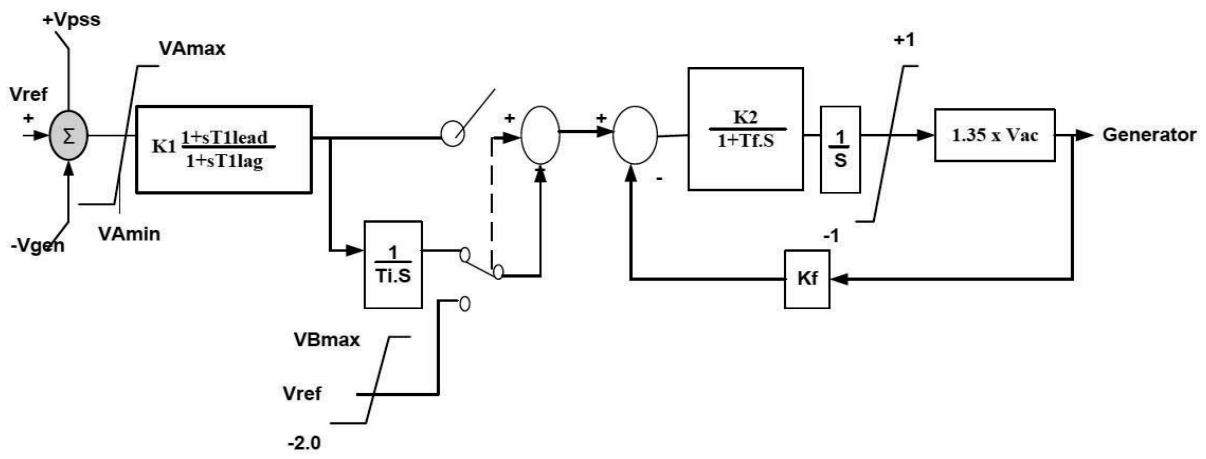

Fig. 2. Block diagram of MEC-5310T excitation system. 


\section{3) Power System Stabilizer (PSS)}

A simplified form of the PSS shown in Fig. 3 can be obtained by neglecting the shaft speed measurement and only measuring the generator real power $P_{e}$ as shown in Fig. 3. This type of PSS was adopted in this real practical model of Al-Zara Thermal Power Station. It includes the following components ${ }^{[2,11]}$ :

- Signal and low pass filter

- Phase compensator

- Gain

- Limiter

The excitation system and power system stabilizer (PSS) variables are defined in Appendix 1.

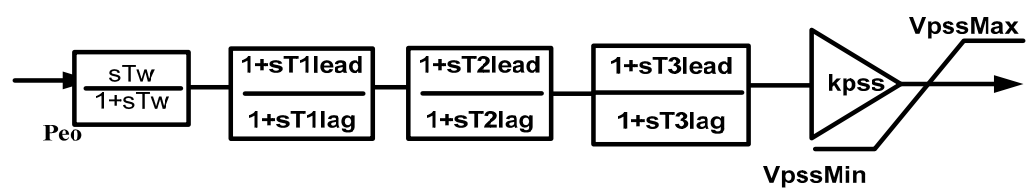

Fig. 3. Block diagram of the CPSS in real study (ZTPS).

The main idea of power system stabilization is to recognize that in the steady-state, that is when the speed deviation is zero or nearly zero, the voltage controller should be driven by the voltage error $\Delta V$ only. However, in the transient state the generator speed is not constant, the rotor swings and $\Delta V$ undergoes oscillations caused by the change in rotor angle. The purpose of the PSS is to add an additional signal which compensates for the $\Delta V$ oscillations and provides a damping component that is in phase with $\Delta \omega$. In the steady state $V_{P S S}$ must be equal to zero so that it doesn't change the voltage regulation process ${ }^{[2]}$. The general structure of the PSS with Excitation system is shown in Fig. 4.

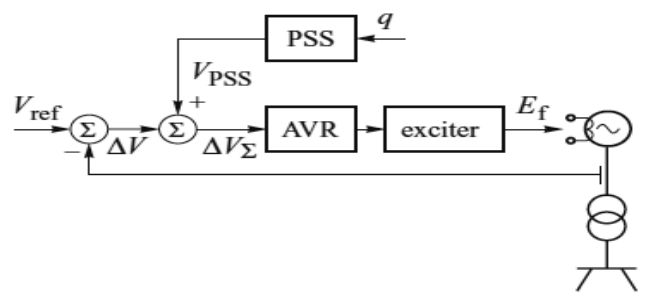

Fig. 4. General structure of the PSS with excitation system. 


\section{Design a Power-Based Stabilizer}

To enhance the contribution of PSS in system stability of Al-Zara Thermal Power Station, a power-based, Integral-of-Accelerating-PowerShaft speed, stabilizer will be designed which gives the best damping of power swing and stability of signals compared with origin form of PSS that based on the electrical power input $\left(P_{e}\right)$ only ${ }^{[18]}$. Figure 5 shows the new formula of PSS, namely proposed PSS where $G(s)$ is the transfer function of a Torsional filter (series of low and high pass filters).

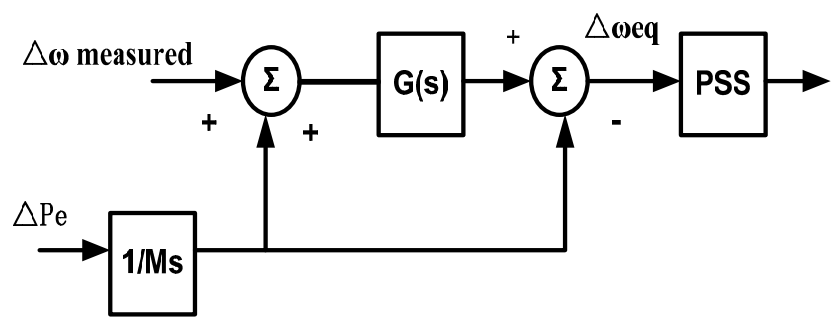

Fig. 5(a). Block diagram of the proposed PSS based on $\Delta \omega$ and Pe.

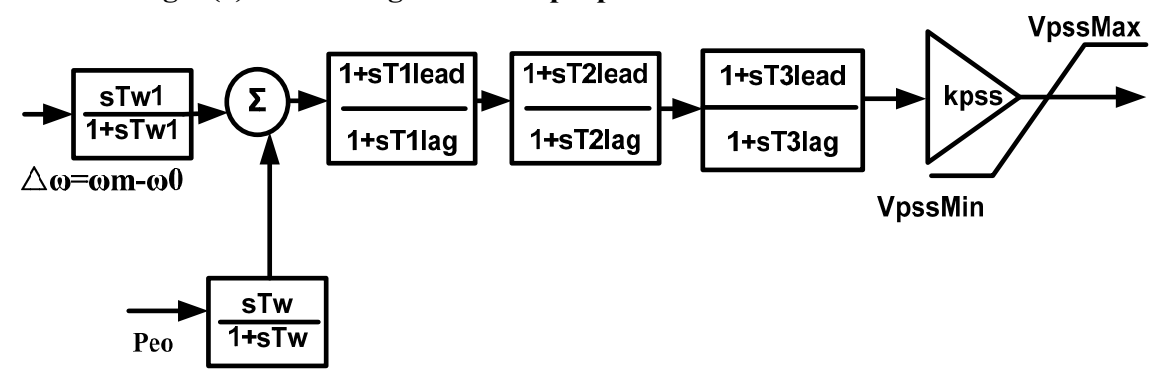

Fig. 5(b). Detailed block diagram of the proposed PSS based on $\Delta \omega$ and Pe.

Thus, the output voltage of the CPSS can be formulated by the following equation:

$$
V_{P S S}=K_{P S S} \frac{1+s T_{3 l e a d}}{1+s T_{3 l a g}} \frac{1+s T_{2 l e a d}}{1+s T_{2 l a g}} \frac{1+s T_{1 \text { lead }}}{1+s T_{1 \text { lag }}}\left(\frac{s T_{w}}{1+s T_{w}} P_{e}+\frac{s T_{w 1}}{1+s T_{w 1}} \Delta \omega\right)
$$

It is worth mentioning that the PSS and Exciter parameters have to be designed to achieve $1 \mathrm{pu}$ for the exciter terminal voltage with minimum settling time and to maintain it at this value with minimum load angle delta and rotor speed deviations after the perturbation so as to improve the power system stability. Note that the most important 
problem in Al-Zara Thermal Power Station is the instability of exciter terminal voltage which varies between $1 \mathrm{pu}$ and $1.5 \mathrm{pu}$.

Therefore the multi-objective optimization function can be formulated as follows:

$$
\min _{K_{P S S}, T_{(1,2,3) \text { lead }}, T_{(1,2,3) \text { lag }}, K_{a}, T_{a}, T_{b}, T_{c}, K_{f}, T_{f}} J=W_{v t} J_{1}+W_{\omega m} J_{2}+W_{t s} J_{3}
$$

One choice of such function is based on the sum of the squared error where error here means the deviation in the variable ${ }^{[19]}$. The individual objective function is expressed as:

$$
\begin{aligned}
& J_{1}=\left(v t_{\text {desired }}-v t_{\text {real }}\right)^{2} \\
& J_{2}=\left(\omega m_{\text {desired }}-\omega m_{\text {real }}\right)^{2} \\
& J_{3}=\left(t s_{\text {desired }}-t s_{\text {real }}\right)^{2}
\end{aligned}
$$

Where $J_{1}$ is the terminal voltage of the exciter $(v t), J_{2}$ is the angular speed shaft ( $\omega m), J_{3}$ is the settling time ( $\left.t s\right)$.

The coefficients $W_{v t}, W_{\omega m}$ and $W_{t s}$ are used to weigh the importance of each of the three quantities and to balance these terms to more or less the same order of magnitude.

The proposed approach employs the continuous genetic algorithm (real coded GA) to solve this optimization problem and search for optimal set of PSS and Excitation system parameters.

\section{Genetic Algorithm}

The genetic algorithm is a probabilistic, random-guided search technique inspired by the Darwinian theory of evolution, which employs the "survival of the fittest" concept of natural biology ${ }^{[19]}$. In GAs, the features characterizing an individual are often binary coded in bits and concatenated as a string. The string package made from different combinations of bits is referred to as a point in the solution space. The fundamental operations of a GA are the following ${ }^{[20]}$ :

1. Initialization: The GA does not work with a single string but with a population of strings, which evolves iteratively by generating new 
individuals taking the place of their parents. To begin, the individuals of the initial population are generated randomly. In our application, each string does code a set of PSS and Exciter parameters.

The use of real-valued genes in GA is claimed by Wright ${ }^{[21]}$ to offer a number of advantages in numerical function optimization over binary encodings.

Efficiency of the GA is increased as there is no need to convert chromosomes to phenotypes before each function evaluation.

2. Time-domain Simulation: Using the set of PSS and Exciter parameters, a time-domain simulation of Al-Zara Thermal Power Station model with proposed PSS and under wide range of operating conditions and various fault disturbances is performed and the fitness value is determined.

3. Objective Function: The performance of each structure is evaluated according to its 'fitness', which is defined as the non-negative figure of merit to be maximized.

4. Genetic Operations: With the evaluation of the fitness function of all individuals, the GA generates a new and improved population from the old one. Most commonly used operations are the following:

a. Reproduction: It is an operation whereby an old string is copied into a 'mating pool' according to its fitness. More highly fitted strings receive a higher number of copies in the next generation.

b. Crossover: Crossover exchanges genetic material from two parent chromosomes, allowing their beneficial genes to be combined in their offspring.

c. Mutation: It is an operation which is able to create new genetic material in the population, changing some chromosomes according to a probabilistic law.

The computational flow chart of the GA optimization approach is shown in Fig. $6^{[22]}$.

\section{Piecewise Cubic Hermite Interpolation}

Interpolating cubic splines are popular for fitting data because they use low-order polynomials that allow a curve to pass through two 
specified endpoints with specified derivatives at each endpoint (Fig. 7) ${ }^{[23]}$.

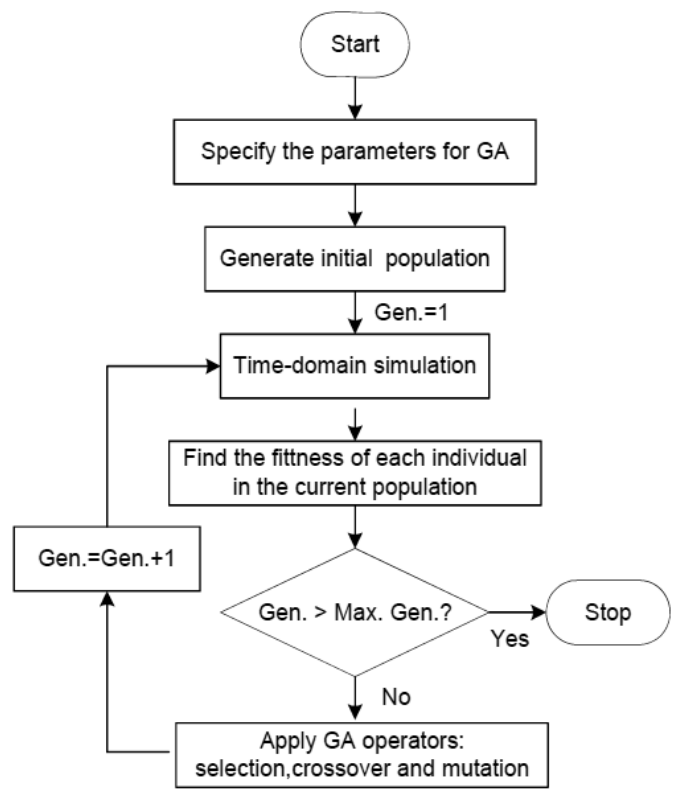

Fig. 6. Flowchart of the genetic algorithm.

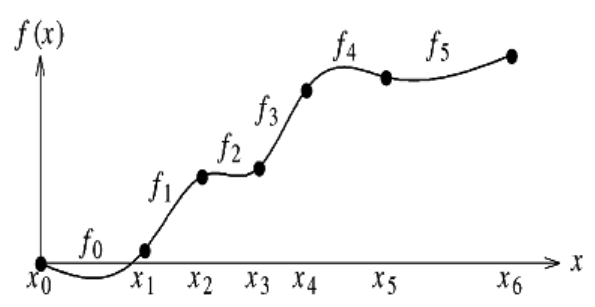

(a) non-monotone spline

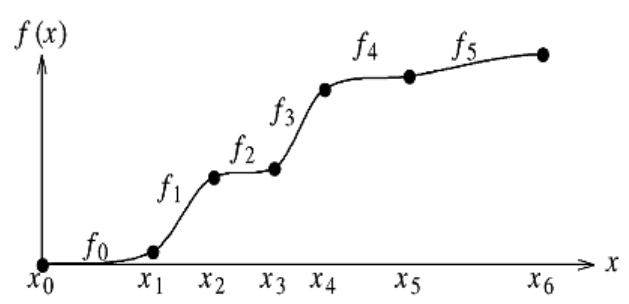

(b) monotone spline

Fig. 7. Interpolating cubic splines.

A cubic spline $f(\chi)$ interpolating on the partition $\chi_{0}<\chi_{1}<\cdots<\chi_{n-1}$ is a function for which $f\left(\chi_{k}\right)=y_{k}$. It is a piecewise polynomial function that consists of $n-1$ cubic polynomials $f_{k}$ defined on the ranges $\left[\chi_{k}, \chi_{k+1}\right]$. Furthermore, each $f_{k}$ is joined at $\chi_{k}$, for $k=1,2, \cdots, n-2$, such that $y_{k}^{\prime}=f^{\prime}\left(\chi_{k}\right)$ and $y_{k}^{\prime \prime}=f^{\prime \prime}\left(\chi_{k}\right)$ are continuous. 
The $k^{\text {th }}$ polynomial curve, $f_{k}$, is defined over the fixed interval $\left[\chi_{k}, \chi_{k+1}\right]$ and has the cubic form:

$$
f_{k}(x)=a_{k}\left(x-x_{k}\right)^{3}+b_{k}\left(x-x_{k}\right)^{2}+c_{k}\left(x-x_{k}\right)+d_{k}
$$

where:

$$
\begin{aligned}
& a_{k}=\frac{1}{\Delta x_{k}^{2}}\left(-2 \frac{\Delta y_{k}}{\Delta x_{k}}+y_{k}^{\prime}+y_{k+1}^{\prime \prime}\right) \\
& b_{k}=\frac{1}{\Delta x_{k}}\left(3 \frac{\Delta y_{k}}{\Delta x_{k}}-2 y_{k}^{\prime}-y_{k+1}^{\prime}\right) \\
& c_{k}=y_{k}^{\prime} \\
& d_{k}=y_{k}
\end{aligned}
$$

Unwanted fluctuations may be avoided altogether by a method using piecewise cubic polynomials having only first derivative continuity. It is designed especially for monotonic data ${ }^{[24]}$.

The goal of this method in our work is to determine the smoothest possible curve that passes through the optimal data set of PSS and Excitation parameters which are given by GA, while simultaneously satisfying the monotonicity constraint.

\section{Simulation and Results}

The proposed control scheme of the present work aims at developing the PSS and Exciter parameters, which assures the desired relative stability for the practical case study, Al-Zara Thermal Power Station under different loading conditions (heavy, lagging, nominal, leading p.f) with large perturbation. The objective function is evaluated for each individual case by simulating the system dynamic model (ZTPS) considering a 5-cycle three phase fault at the generator terminal bus bar at $t=90 \mathrm{sec}$.

\section{Case I: Application of GA Optimization Technique}

The Genetic Algorithm has been programmed in Matlab2009b software based on continuous search algorithm ${ }^{[19]}$. The continuous 
genetic algorithm (real coded GA) is inherently faster than the binary GA, because the chromosomes do not have to be decoded prior to the evaluation of the cost function. This algorithm is used to obtain the controller parameters that minimize the objective function described in Eq. (8).

The optimization process is repeated at all loading conditions $(0.7$, $0.85,0.9,1.0) \mathrm{pu}$. The parameters for GA optimization routines are given in Table 1.

Table 1. Parameters for GA optimization routines.

\begin{tabular}{|l|c|}
\hline Mutation rate & 0.8 \\
\hline Number of variables & 15 \\
\hline Population size & 20 \\
\hline Maximum generation & 300 \\
\hline Generation gap & 0.8 \\
\hline Precision & 20 \\
\hline
\end{tabular}

It is worth noting here that the population and generation sizes could have been chosen much larger. However, due to the large simulation time taken by Simulink, this was not possible.

Note here that even with the relatively medium population and generation sizes chosen in this case, the realization of GA optimization process consumed $3333.33 \mathrm{sec}$. of CPU time. However, to ensure that the GA search converges fast enough, we chose a relatively high crossover, mutation rates and an appropriate choice range of PSS and Exciter parameters.

The performance of the excitation voltage $\left(V_{f}\right)$, the rotor speed $\left(\omega_{m}\right)$ and the load angle delta in response to a 5-cycle 3-phase short circuit for the five operating conditions at the proposed PSS, CPSS and GA based PSS and Exciter are depicted in Fig. 8-11 and Table 2.

Table 2. The performance of dynamic system for ZTPS.

\begin{tabular}{|c|c|l|l|l|}
\hline \multirow{4}{*}{ Parameters } & $\begin{array}{c}\text { Operating } \\
\text { Conditions } \\
\text { (p.f) }\end{array}$ & CPSS & $\begin{array}{c}\text { Proposed } \\
\text { PSS }\end{array}$ & GAPSS \\
\hline \multirow{4}{*}{$\begin{array}{c}\text { ts, Vf (at steady state) } \\
\text { ts, Vf (after 3-phase } \\
\text { fault) }\end{array}$} & $0.7 \mathrm{pu}$ & $20 \mathrm{sec}, 1.4 \mathrm{pu}$ & $57 \mathrm{sec}, 1 \mathrm{pu}$ & $45 \mathrm{sec}, 1 \mathrm{pu}$ \\
\cline { 2 - 5 } & $0.85 \mathrm{pu}$ & $25 \mathrm{sec}, 1 \mathrm{pu}$ & $40 \mathrm{sec}, 1.5 \mathrm{pu}$ & $25 \mathrm{sec}, 1 \mathrm{pu}$ \\
\cline { 2 - 5 } & $0.9 \mathrm{pu}$ & $75 \mathrm{sec}, 1 \mathrm{pu}$ & $35 \mathrm{sec}, 1 \mathrm{pu}$ & $52 \mathrm{sec}, 1 \mathrm{pu}$ \\
\cline { 2 - 5 } & $1.0 \mathrm{pu}$ & $75 \mathrm{sec}, 1.5 \mathrm{pu}$ & $70 \mathrm{pec}, 1 \mathrm{pu}$ & $45 \mathrm{sec}, 1 \mathrm{pu}$ \\
\cline { 2 - 5 } & $15 \mathrm{sec}, 1.7 \mathrm{pu}$ & $75 \mathrm{pec}, 1 \mathrm{pu}$ & $11 \mathrm{sec}, 1 \mathrm{pu}$ \\
\cline { 2 - 5 } & $75 \mathrm{sec}, 1 \mathrm{pu}$ & $20 \mathrm{sec}, 1 \mathrm{pu}$ & $54 \mathrm{sec}, 1 \mathrm{pu}$ \\
\hline
\end{tabular}



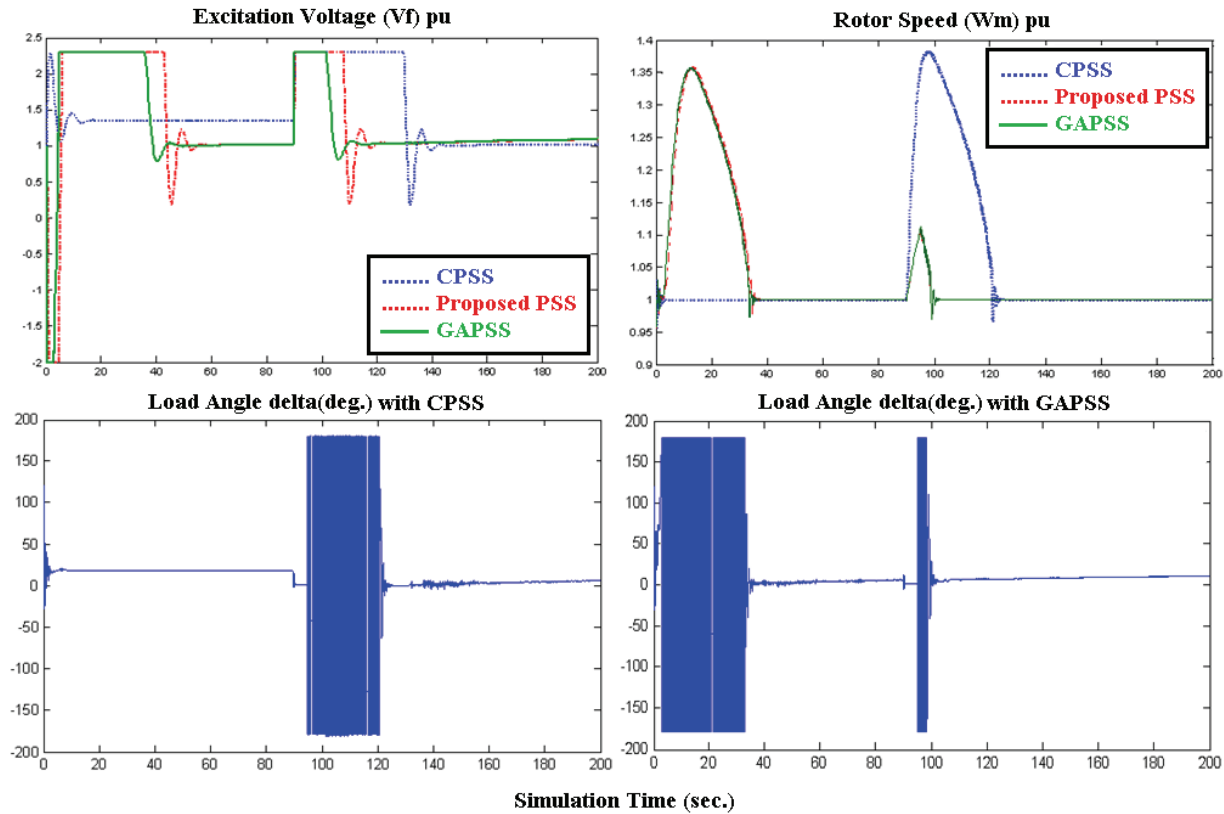

Fig. 8. The performance of ZTPS for leading load (0.7 pu) p.f.
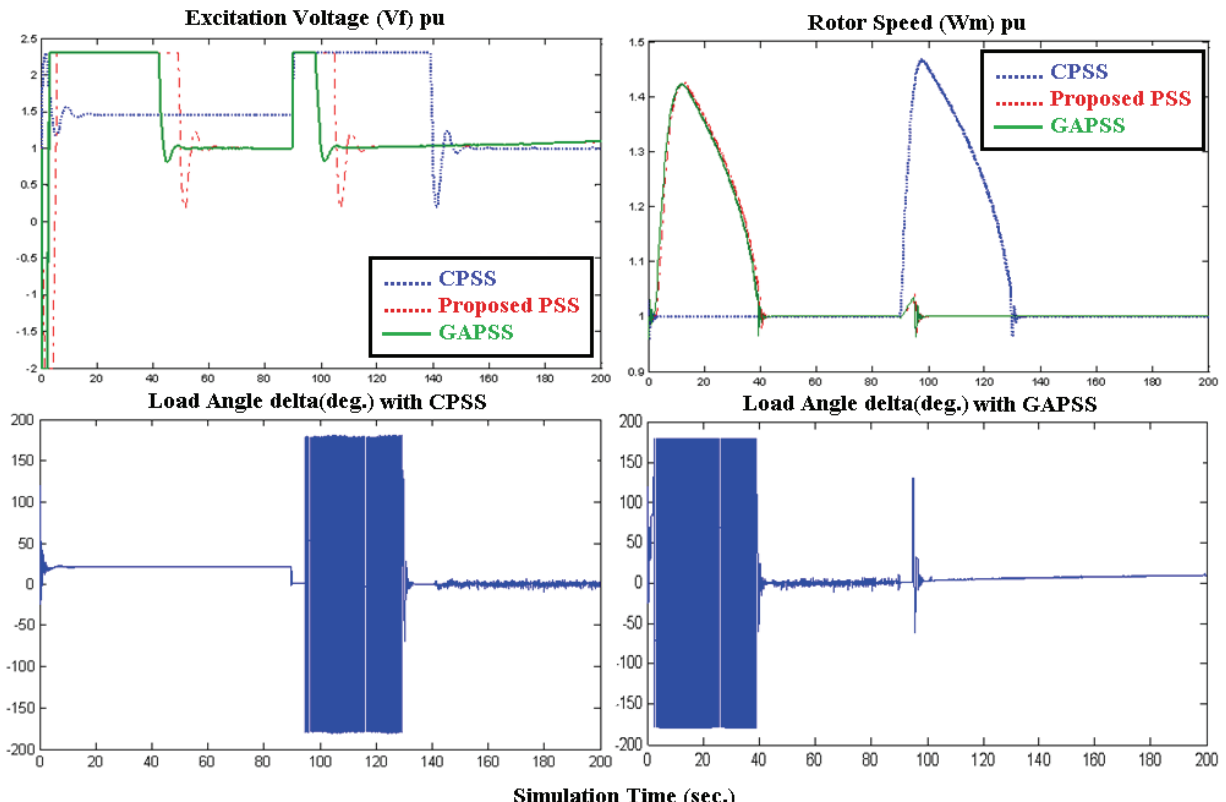

Fig. 9. The performance of ZTPS for lagging load ( $0.85 \mathrm{pu})$ p.f. 

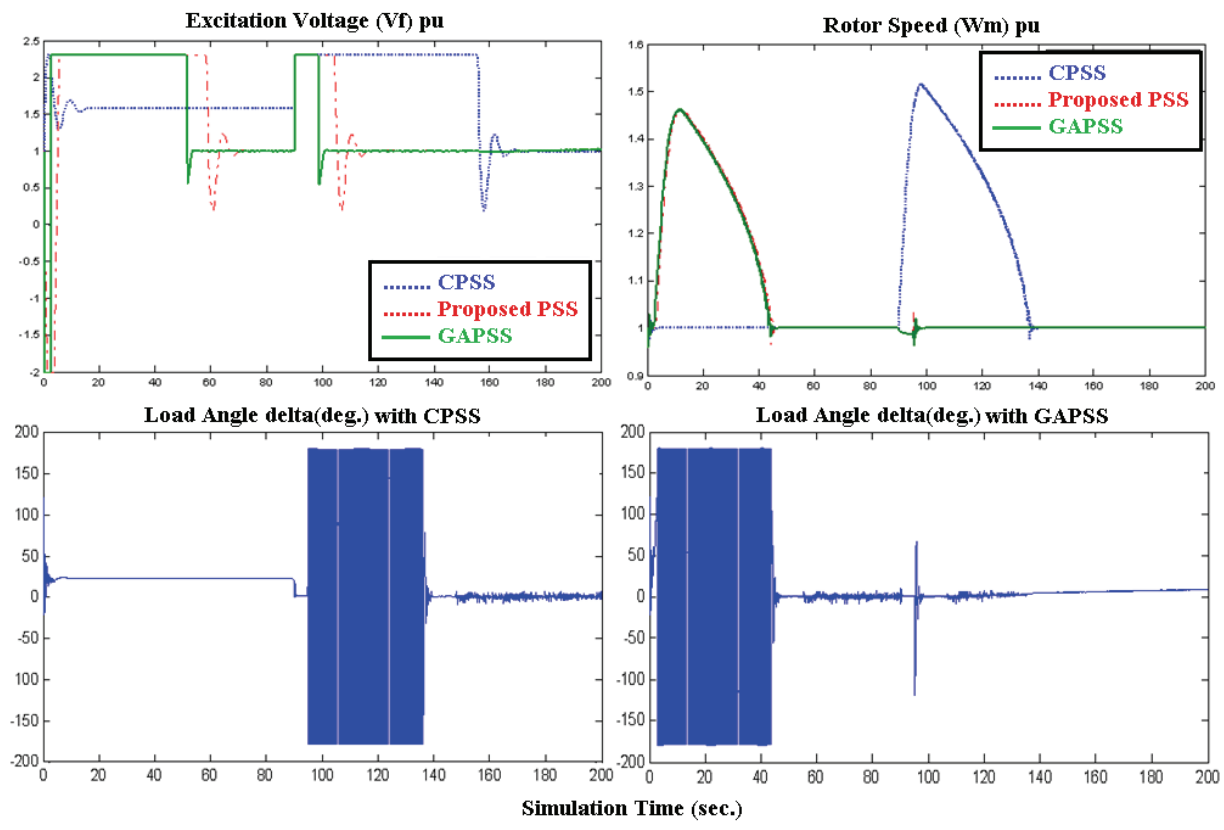

Fig. 10. The performance of ZTPS for nominal load (0.9 pu) p.f.
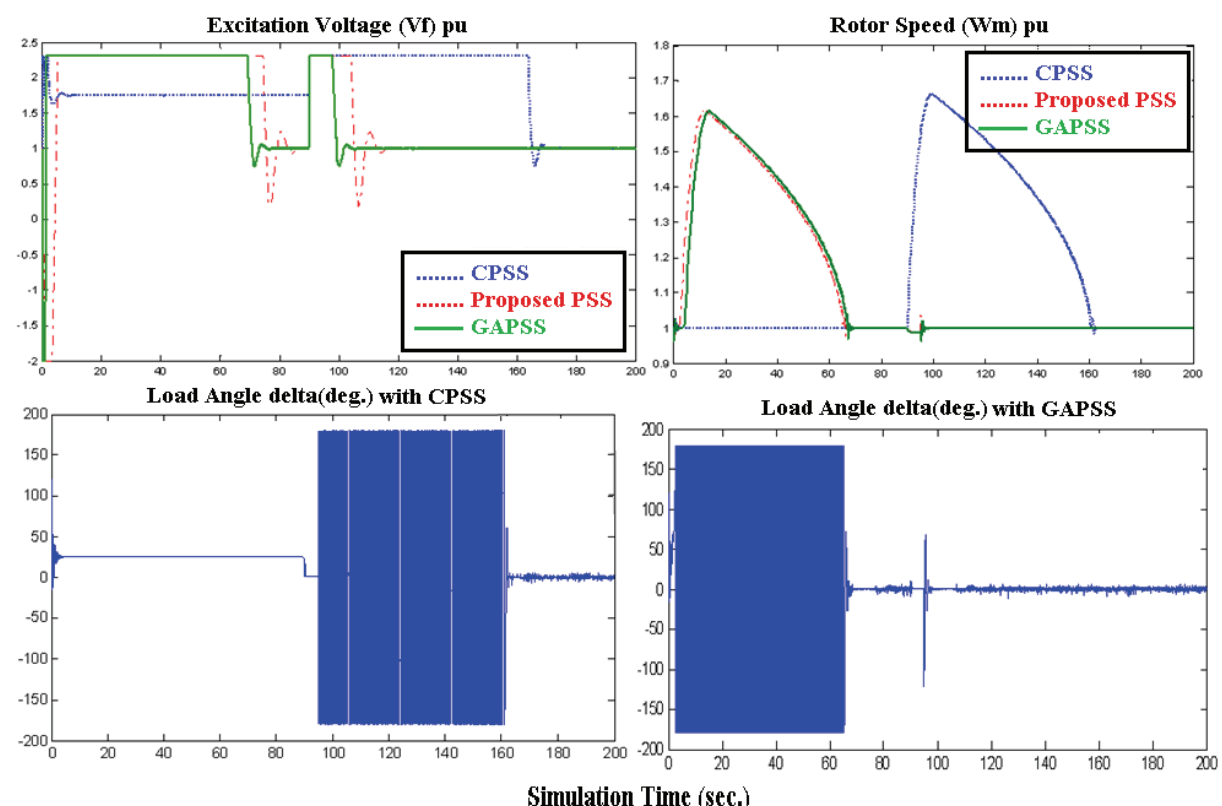

Fig. 11. The performance of ZTPS for heavy load (1.0 pu) p.f. 
From the above results, we notice that the responses with conventional PSS is unstable while newly proposed PSS in this study is highly oscillatory in the transient state but it covers to a stable state in the steady state. While it is clear from test results for various operating conditions with perturbation that the GA stabilizer is able to provide good damping over a wide operating range and improves the overall system performance in both transient and steady state.

It should be noted that the oscillations in load angle in Fig. 8-11 at the beginning of operation are normal. However, with the proposed controller, these oscillations are highly damped when an error is introduced and this point is very important for the operation of the power generation.

\section{Case II: Results of Piecewise Cubic Hermite Interpolation}

We first describe a set of conditions and data set obtained by GA that forms the basis of the monotonic cubic. The conditions are simplified and consolidated to yield a fast method for determining monotonicity

Then, we use the pchip function to perform piecewise cubic Hermite interpolation within the vectors $\mathrm{x}$ and $\mathrm{y}$. These methods preserve monotonicity and the shape of the data. Thirty equally space points covering the operating range ( 0.7 to $1 \mathrm{pu}) \mathrm{p} . \mathrm{f}$ are selected to find the PSS and Exciter parameters through an interpolation process.

To evaluate and examine these values, one point of operating conditions from the interpolation results is selected $(0.75 \mathrm{pu})$ and compared with GA results at the same point $(0.75 \mathrm{pu})$. We noticed very similar values of parameters at this point as shown in Appendix 2, and it is also highlighted in GA results.

The performance of the Excitation volt $\left(V_{f}\right)$ and the rotor speed $\left(\omega_{m}\right)$ in response to a 5-cycle 3-phase short circuit for the operating conditions $(0.75,0.95)$ from interpolation results are depicted in Fig. 12.

According to the figures above we can conclude that the system is stable and has a similar robustness to the GA results given before. Therefore, we can use interpolation technique to reduce the time consuming by GA analysis but we still use the same data set obtained by GA. In this technique, we can reduce the time consumed by GA to 
optimize the parameters of PSS and Exciter for a wide range of operating conditions.
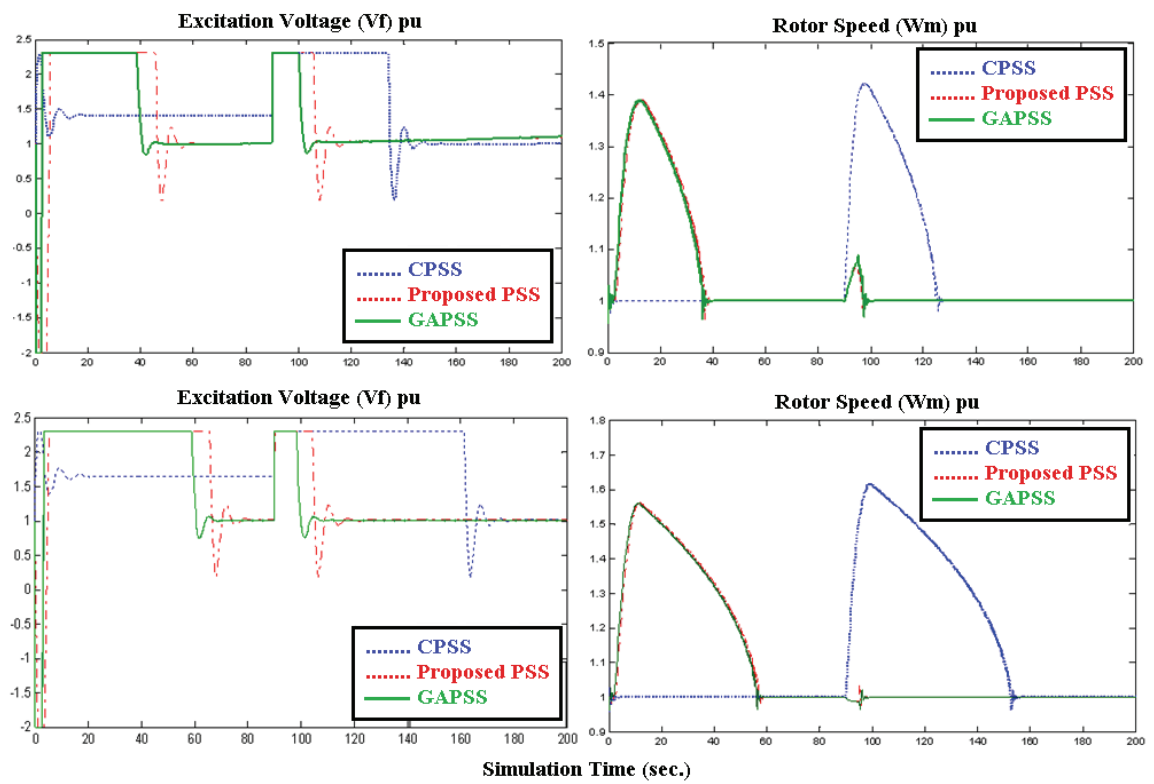

Fig. 12. The performance of ZTPS from interpolation results ( $0.75 \mathrm{pu}$ and $0.95 \mathrm{pu})$ p.f.

\section{Conclusion}

In this paper, the design of PSS and Exciter was discussed for power system dynamic stability improvement of a practical case study, Al-Zara Thermal Power Station Generation in Syria. The design problem was formulated as an optimization problem and the real coded genetic algorithm was used for searching optimized parameters. The design was performed for four operating conditions and large perturbation, a three phase short-circuit fault occurs at the generator bus bar terminal is considered in the present study for objective function calculation. The dynamic performance of proposed PSS and GAPSS have also been compared with a conventionally designed PSS to show its superiority, effectiveness and robustness of the GA optimized PSS controller and their ability to provide efficient damping of low frequency oscillations. A cubic Hermite interpolation algorithm is employed to determine the smoothest possible curve that passes through its data set obtained by GA while simultaneously satisfying the monotonicity constraint. Checked by a comparison with the performance of dynamic system in response to a 
5-cycle 3-phase short circuit at genetic algorithm, the results are encouraging.

\section{References}

[1] Rogers, G., Power System Oscillations, Boston: Kluwer Academic Publishers (2000).

[2] Jan, M.J.W. and Bialek J.B.R., Power System Dynamics: Stability and Control, $2^{\text {nd }}$ Ed., John Wiley \& Sons, Ltd (2008).

[3] Song, Y.H. and Johns, A.T., Flexible AC Transmission Systems (FACTS), The Institution of Electrical Engineers, London, United Kingdom (1999).

[4] Kundur, P., Klein, M., Rogers, G.J. and Zywno, M.S., Application of Power System Stabilizers for Enhancement of Overall System Stability, IEEE Trans. on Power Systems, 4(2): 614-626 (1989).

[5] Abdel-Magid, Y.L. and Abido, M.A., Coordinated Design of a PSS and a SVC-Based Controller to Enhance Power System Stability, Electrical Power \& Energy Systems, 25: 695704 (2003).

[6] Shivakumar, R. and Lakshmipathi, R., Implementation of an Innovative Bio Inspired GA and PSO Algorithm for Controller design Considering Steam GT Dynamics, International Journal of Computer Science Issues, 7(3) (2010).

[7] Taher, S.A. and Shemshadi, A., Design of Robust Fuzzy Logic Power System Stabilizer, World Academy of Science, Engineering and Technology, 2(2): 8-14 (2007).

[8] Precup R.E., Tomescu, M.L. and Preitl, St., Fuzzy Logic Control System Stability Analysis Based on Lyapunov's Direct Method, Int. J. of Computers, Communications \& Control, IV(4): 415- 426 (2009).

[9] Rahim, A.H., Nowicki, E.P. and J.M. Bakhashwain1., Fuzzy STATCOM Control Strategies for Power System Stabilization, ACSE Journal, 6(2) (2006).

[10] [10] Ahadian, J., Jalali, M. , Pouaghababa, R. and Nouhi, M., Power System Stabilizers Optimization Based on Neural Network using linear Optimal Control, University of Pitesti Electronics and Computer Science, Scientific Bulletin, 8(2) (2008).

[11] Alkhatib, H. and Duveau, J., Robust Design of Power System Stabilizers Using Adaptive Genetic Algorithms, World Academy of Science, Engineering and Technology, 64(47): 267$272(2010)$.

[12] Aliakbar Golkar, M. and Zarringhalami, M., Coordinated Design of PSS and STATCOM Parameters for Power System Stability Improvement Using Genetic Algorithm, Iranian Journal of Electrical Computer Engineering, 8(2) (2009).

[13] Choucha, A., Alkhatib, H., Duveau, J., Hellal, A. and Arif, S., Multiobjective GA to Simultaneous Coordinated Tuning PSS and Location for Multimachine Power Systems, Proc. XVIII International Conference on Electrical Machines ICEM'08, Vilamoura (2008).

[14] Sebaa, K. and Boudour, M., Optimal locations and Tuning of Robust Power system Stabilizer using Genetic Algorithms, Electric Power Systems Research, 79: 406-419 (2009).

[15] Mohan Mathur, R. and Varma, R.K., Thyristor-Based FACTS Controllers for Electrical Transmission System, John Wiley \& Sons, INC. (2002).

[16] Attikas, R.H.T., Excitation System Models of Generators of Balti and EESTI Power Plants, Oil Shale, Estonian Academy Publishers, 24(2): 285-295 (2007).

[17] Mitsubishi Electric Corporation, Al-Zara Thermal Power Plant: Site Training Text for Electric Maintenance, Mitsubishi Electric Corporation (2001).

[18] Al-Mustfa, R., Fattouh, A. and Hashim, W., A Comparative Analysis of the Effect of the Power System Stabilizer on the Dynamic Stability of the Electric Power Generation Stations in Syria, Proc. $6^{\text {th }}$ International Conference on Electrical Engineering: 375-381 (2010).

[19] Randy, L.H. and Sue Ellen Haupt, Practical Genetic Algorithms, A John Wiley \& Sons INC. (2004). 
[20] Sebaa, K. and Boudour, M., Optimal Locations and Tuning of Robust Power System Stabilizer using Genetic Algorithm, Electric Power Systems Research, 79: 406-419 (2009).

[21] Wright, A.H., Genetic Algorithms for Real Parameter Optimization, Foundations of Genetic Algorithms, J. E. Rawlins (Ed.), Morgan Kaufmann, pp: 205-218 (1991).

[22] Sidhartha, P. and Narayana, P.P., MATLAB/SIMULINK Based Model of Single-Machine Infinite-Bus with TCSC for Stability Studies and Tuning Employing GA, International Journal of Computer Science and Engineering: 50-59 (2007).

[23] Wolberg, G. and Alfy, I., An Energy-Minimization Framework for Monotonic Cubic Spline Interpolation, Journal of Computational and Applied Mathematics: 145-188 (2002).

[24] Embree, M., Numerical Analysis, Rice University (2009). 


\section{Appendix 1}

\section{Nomenclature}

\begin{tabular}{|c|c|}
\hline $\mathrm{Xd}, \mathrm{Xq}$ & d- and q-axis synchronous reactance \\
\hline$X^{\prime} d, X^{\prime} q$ & $\mathrm{~d}$ - and q-axis transient reactance \\
\hline$X^{\prime \prime} d, X^{\prime \prime q}$ & $\mathrm{~d}$ - and q-axis sub-transient reactance \\
\hline $\mathrm{Ra}$ & Stator resistance \\
\hline $\mathrm{Xl}$ & Stator leakage inductance \\
\hline T'do,T'qo & d- and q-axis transient open circuit time constant \\
\hline T"do, T"qo & d- and q-axis sub-transient open circuit time constant \\
\hline M, H & Stored energy at rated speed, inertia constant \\
\hline $\mathrm{F}, \mathrm{D}$ & Friction and Damping coefficient \\
\hline$E_{f}$ & Equivalent excitation voltage \\
\hline $\boldsymbol{\omega}_{s}$ & Synchronous speed \\
\hline$\Delta \omega$ & Angle of q-axis with respect to system \\
\hline$\delta$ & Rotor angle with respect to the infinite bus, electrical radians \\
\hline$P e$ & Synchronous output active power \\
\hline$P m$ & Synchronous mechanical power \\
\hline$V d, q$ & d- and q-axis synchronous voltage \\
\hline$V d$ & $\begin{array}{l}\text { d-axis component of the transient internal emf proportional to flux } \\
\text { linkages in the q-axis solid steel rotor body }\end{array}$ \\
\hline$V q$ & $\begin{array}{l}\text { q-axis component of the transient internal emf proportional to the } \\
\text { field winding flux linkages }\end{array}$ \\
\hline$V^{\prime \prime} d$ & $\begin{array}{l}\text { d-axis component of the sub-transient internal emf proportional to } \\
\text { flux linkages in the q-axis damper winding and -axis solid steel rotor } \\
\text { body }\end{array}$ \\
\hline$V^{\prime \prime} q$ & $\begin{array}{l}\text { q-axis component of the sub-transient internal emf proportional to the } \\
\text { total flux linkages in the d-axis damper winding and the field winding }\end{array}$ \\
\hline $\mathrm{K} 1, \mathrm{~K} 2$ & Forward gain of Excitation system \\
\hline $\mathrm{TF}$ & Feedback time constant of Excitati n System \\
\hline $\mathrm{KF}$ & Feedback gain of Excitation System \\
\hline $\mathrm{Ti}$ & Integral time constant of Excitation System \\
\hline Tlead, Tlag & Time constant of transient gain reduction \\
\hline VAMAX,VAMIN & Regulator internal signal limits \\
\hline Tw,Tw1 & low pass filter constant \\
\hline $\begin{array}{l}\mathrm{T}(1,2,3) \text { lead, } \\
\mathrm{T}(1,2,3) \text { lag }\end{array}$ & Time constants of power system stabilizer \\
\hline Kpss & Gain power system stabilizer \\
\hline
\end{tabular}


Appendix 2

The Interpolation results with GA results.

\begin{tabular}{|c|c|c|c|c|c|c|c|c|}
\hline kpss & $\mathbf{1 . 7}$ & 1.75 & 1.798 & 1.842 & 1.883 & $\mathbf{1 . 9 2}$ & $\mathbf{1 . 6 8}$ & 1.952 \\
\hline t6 & $\mathbf{0 . 0 6 7}$ & 0.0668 & 0.0664 & 0.0658 & 0.0652 & $\mathbf{0 . 0 6 4 4}$ & $\mathbf{0 . 0 6 4}$ & 0.0636 \\
\hline t5 & $\mathbf{0 . 8 8}$ & 0.8329 & 0.7952 & 0.7659 & 0.7438 & $\mathbf{0 . 7 2 8}$ & $\mathbf{0 . 8 0 9}$ & 0.7174 \\
\hline $\mathbf{t 4}$ & $\mathbf{0 . 7 8}$ & 0.8243 & 0.8613 & 0.8916 & 0.916 & $\mathbf{0 . 9 3 4 9}$ & $\mathbf{0 . 7 9 2}$ & 0.949 \\
\hline $\mathbf{t 3}$ & $\mathbf{0 . 6 6}$ & 0.611 & 0.571 & 0.54 & 0.517 & $\mathbf{0 . 5}$ & $\mathbf{0 . 7 9 2}$ & 0.489 \\
\hline $\mathbf{t 2}$ & $\mathbf{0 . 7}$ & 0.677 & 0.6576 & 0.6416 & 0.6288 & $\mathbf{0 . 6 1 8 7}$ & $\mathbf{0 . 7 1 4}$ & 0.611 \\
\hline t1 & $\mathbf{0 . 3 3}$ & 0.3355 & 0.3412 & 0.3471 & 0.3532 & $\mathbf{0 . 3 5 9 6}$ & $\mathbf{0 . 2 7}$ & 0.3661 \\
\hline Tw & $\mathbf{3 . 8}$ & 3.8362 & 3.8773 & 3.923 & 3.9728 & $\mathbf{4 . 0 2 6 3}$ & $\mathbf{3 . 3}$ & 4.0832 \\
\hline Tw1 & $\mathbf{2}$ & 1.735 & 1.523 & 1.357 & 1.233 & $\mathbf{1 . 1 4 4}$ & $\mathbf{1 . 0 9 6}$ & 1.084 \\
\hline Tf & $\mathbf{0 . 2}$ & 0.2039 & 0.215 & 0.2327 & 0.256 & $\mathbf{0 . 2 8 4 4}$ & $\mathbf{0 . 5 8 4}$ & 0.317 \\
\hline Kf & $\mathbf{0 . 1 0 4 6}$ & 0.0947 & 0.0866 & 0.08 & 0.0748 & $\mathbf{0 . 0 7 0 9}$ & $\mathbf{0 . 0 6 0 5}$ & 0.0681 \\
\hline Tc & $\mathbf{0 . 0 6 7}$ & 0.0668 & 0.0664 & 0.0658 & 0.0652 & $\mathbf{0 . 0 6 4 4}$ & $\mathbf{0 . 0 6 4}$ & 0.0636 \\
\hline Tb & $\mathbf{0 . 1 2 1 7}$ & 0.1349 & 0.1497 & 0.1661 & 0.1838 & $\mathbf{0 . 2 0 2 7}$ & $\mathbf{0 . 3 5 3 6}$ & 0.2228 \\
\hline Ta & $\mathbf{0 . 2}$ & 0.1824 & 0.1657 & 0.1503 & 0.1362 & $\mathbf{0 . 1 2 3 7}$ & $\mathbf{0 . 0 8 7}$ & 0.113 \\
\hline Ka & $\mathbf{9 7 . 7 4}$ & 98.14 & 98.538 & 98.935 & 99.331 & $\mathbf{9 9 . 7 2 5}$ & $\mathbf{9 7 . 9 7}$ & 100.12 \\
\hline Peo\% & $\mathbf{7 0}$ & 71 & 72 & 73 & 74 & $\mathbf{7 5}$ & $\mathbf{7 5 G A}$ & 76 \\
\hline
\end{tabular}

\begin{tabular}{|c|c|c|c|c|c|c|c|c|}
\hline kpss & 1.981 & 2.004 & 2.022 & $\mathbf{2 . 0 3 5}$ & 2.043 & 2.048 & 2.052 & 2.058 \\
\hline t6 & 0.0627 & 0.0617 & 0.0607 & $\mathbf{0 . 0 5 9 6}$ & 0.0585 & 0.0572 & 0.0556 & 0.0538 \\
\hline t5 & 0.711 & 0.7077 & 0.7065 & $\mathbf{0 . 7 0 6 3}$ & 0.7334 & 0.7981 & 0.8752 & 0.9399 \\
\hline $\mathbf{t 4}$ & 0.9589 & 0.9653 & 0.9686 & $\mathbf{0 . 9 6 9 6}$ & 0.9612 & 0.9396 & 0.9098 & 0.8769 \\
\hline $\mathbf{t 3}$ & 0.482 & 0.479 & 0.478 & $\mathbf{0 . 4 7 7}$ & 0.507 & 0.579 & 0.664 & 0.736 \\
\hline $\mathbf{t 2}$ & 0.6056 & 0.6021 & 0.6003 & $\mathbf{0 . 5 9 9 7}$ & 0.6061 & 0.6215 & 0.6397 & 0.6551 \\
\hline t1 & 0.3728 & 0.3796 & 0.3865 & $\mathbf{0 . 3 9 3 6}$ & 0.4023 & 0.4126 & 0.4226 & 0.43 \\
\hline Tw & 4.143 & 4.2053 & 4.2698 & $\mathbf{4 . 3 3 6}$ & 4.3978 & 4.4578 & 4.5288 & 4.6232 \\
\hline Tw1 & 1.048 & 1.03 & 1.023 & $\mathbf{1 . 0 2 2}$ & 1.125 & 1.37 & 1.663 & 1.908 \\
\hline Tf & 0.353 & 0.3918 & 0.4326 & $\mathbf{0 . 4 7 4 5}$ & 0.5403 & 0.6361 & 0.7362 & 0.815 \\
\hline Kf & 0.0662 & 0.065 & 0.0645 & $\mathbf{0 . 0 6 4 3}$ & 0.0675 & 0.0751 & 0.0842 & 0.0918 \\
\hline Tc & 0.0627 & 0.0617 & 0.0607 & $\mathbf{0 . 0 5 9 6}$ & 0.0585 & 0.0572 & 0.0556 & 0.0538 \\
\hline Tb & 0.2439 & 0.2659 & 0.2885 & $\mathbf{0 . 3 1 1 8}$ & 0.3418 & 0.3793 & 0.4163 & 0.4449 \\
\hline Ta & 0.1043 & 0.0978 & 0.0938 & $\mathbf{0 . 0 9 2 4}$ & 0.0925 & 0.0926 & 0.0929 & 0.093 \\
\hline Ka & 100.51 & 100.9 & 101.29 & $\mathbf{1 0 1 . 6 8}$ & 102.01 & 102.28 & 102.57 & 102.98 \\
\hline Peo\% & 77 & 78 & 79 & $\mathbf{8 0}$ & 81 & 82 & 83 & 84 \\
\hline
\end{tabular}

\begin{tabular}{|c|c|c|c|c|c|c|c|c|}
\hline kpss & $\mathbf{2 . 0 6 7}$ & 2.146 & 2.316 & 2.515 & 2.681 & $\mathbf{2 . 7 5}$ & 2.75 & 2.75 \\
\hline $\mathbf{t 6}$ & $\mathbf{0 . 0 5 1 5}$ & 0.0472 & 0.0406 & 0.0335 & 0.0278 & $\mathbf{0 . 0 2 5 5}$ & 0.0291 & 0.0397 \\
\hline $\mathbf{t 5}$ & $\mathbf{0 . 9 6 7}$ & 0.9532 & 0.9202 & 0.8808 & 0.8478 & $\mathbf{0 . 8 3 4}$ & 0.8345 & 0.8367 \\
\hline $\mathbf{t 4}$ & $\mathbf{0 . 8 4 6}$ & 0.8111 & 0.7684 & 0.7269 & 0.6955 & $\mathbf{0 . 6 8 3}$ & 0.683 & 0.6833 \\
\hline $\mathbf{t 3}$ & $\mathbf{0 . 7 6 6}$ & 0.723 & 0.621 & 0.498 & 0.396 & $\mathbf{0 . 3 5 3}$ & 0.354 & 0.358 \\
\hline $\mathbf{t 2}$ & $\mathbf{0 . 6 6 1 5}$ & 0.6375 & 0.5804 & 0.5122 & 0.4551 & $\mathbf{0 . 4 3 1 1}$ & 0.4312 & 0.4318 \\
\hline $\mathbf{t 1}$ & $\mathbf{0 . 4 3 3}$ & 0.4126 & 0.364 & 0.306 & 0.2574 & $\mathbf{0 . 2 3 7}$ & 0.2381 & 0.242 \\
\hline $\mathbf{T w}$ & $\mathbf{4 . 7 5 4}$ & 5.3248 & 6.4644 & 7.7733 & 8.8517 & $\mathbf{9 . 3}$ & 9.2918 & 9.2495 \\
\hline Tw1 & $\mathbf{2 . 0 1 1}$ & 1.906 & 1.657 & 1.36 & 1.11 & $\mathbf{1 . 0 0 6}$ & 1.006 & 1.007 \\
\hline Tf & $\mathbf{0 . 8 4 7}$ & 0.8372 & 0.8121 & 0.7779 & 0.7408 & $\mathbf{0 . 7 0 7}$ & 0.6767 & 0.6458 \\
\hline Kf & $\mathbf{0 . 0 9 5}$ & 0.0866 & 0.0667 & 0.0429 & 0.023 & $\mathbf{0 . 0 1 4 6}$ & 0.0146 & 0.0147 \\
\hline Tc & $\mathbf{0 . 0 5 1 5}$ & 0.0472 & 0.0406 & 0.0335 & 0.0278 & $\mathbf{0 . 0 2 5 5}$ & 0.0291 & 0.0397 \\
\hline Tb & $\mathbf{0 . 4 5 7}$ & 0.4581 & 0.4589 & 0.4595 & 0.4599 & $\mathbf{0 . 4 6}$ & 0.4578 & 0.4515 \\
\hline Ta & $\mathbf{0 . 0 9 3 1}$ & 0.0884 & 0.0772 & 0.0637 & 0.0522 & $\mathbf{0 . 0 4 7}$ & 0.0464 & 0.0458 \\
\hline $\mathbf{K a}$ & $\mathbf{1 0 3 . 6}$ & 112.43 & 132.4 & 155.98 & 175.65 & $\mathbf{1 8 3 . 8 8}$ & 183.85 & 183.6 \\
\hline $\mathbf{P e o \%}$ & $\mathbf{8 5}$ & 86 & 87 & 88 & 89 & $\mathbf{9 0}$ & 91 & 92 \\
\hline
\end{tabular}




\begin{tabular}{|c|c|c|c|c|c|c|c|c|}
\hline kpss & 2.75 & 2.749 & 2.749 & 2.748 & 2.747 & 2.745 & 2.743 & $\mathbf{2 . 7 4}$ \\
\hline $\mathbf{t 6}$ & 0.0568 & 0.0801 & 0.1091 & 0.1435 & 0.1829 & 0.2269 & 0.275 & $\mathbf{0 . 3 2 7}$ \\
\hline $\mathbf{t 5}$ & 0.8411 & 0.8487 & 0.86 & 0.8758 & 0.8969 & 0.9239 & 0.9577 & $\mathbf{0 . 9 9 9}$ \\
\hline $\mathbf{t 4}$ & 0.684 & 0.6854 & 0.6877 & 0.6911 & 0.6958 & 0.7021 & 0.7103 & $\mathbf{0 . 7 2 0 4}$ \\
\hline $\mathbf{t 3}$ & 0.368 & 0.386 & 0.414 & 0.456 & 0.512 & 0.587 & 0.682 & $\mathbf{0 . 7 9 9}$ \\
\hline $\mathbf{t 2}$ & 0.4335 & 0.4368 & 0.4422 & 0.4503 & 0.4616 & 0.4767 & 0.496 & $\mathbf{0 . 5 2 0 1}$ \\
\hline $\mathbf{t 1}$ & 0.2497 & 0.2624 & 0.281 & 0.3067 & 0.3403 & 0.3831 & 0.436 & $\mathbf{0 . 5}$ \\
\hline Tw & 9.1463 & 8.9555 & 8.6504 & 8.2042 & 7.5903 & 6.782 & 5.7524 & $\mathbf{4 . 4 7 5}$ \\
\hline Tw1 & 1.011 & 1.018 & 1.03 & 1.047 & 1.072 & 1.104 & 1.146 & $\mathbf{1 . 1 9 8}$ \\
\hline Tf & 0.6143 & 0.5822 & 0.5496 & 0.5162 & 0.4822 & 0.4475 & 0.4121 & $\mathbf{0 . 3 7 6}$ \\
\hline Kf & 0.015 & 0.0156 & 0.0165 & 0.0179 & 0.0199 & 0.0225 & 0.0258 & $\mathbf{0 . 0 3}$ \\
\hline Tc & 0.0568 & 0.0801 & 0.1091 & 0.1435 & 0.1829 & 0.2269 & 0.275 & $\mathbf{0 . 3 2 7}$ \\
\hline Tb & 0.4413 & 0.4276 & 0.4106 & 0.3908 & 0.3684 & 0.3438 & 0.3172 & $\mathbf{0 . 2 8 9}$ \\
\hline Ta & 0.0453 & 0.0449 & 0.0445 & 0.0443 & 0.0441 & 0.0439 & 0.0438 & $\mathbf{0 . 0 4 3 8}$ \\
\hline Ka & 182.94 & 181.66 & 179.55 & 176.39 & 171.98 & 166.12 & 158.6 & $\mathbf{1 4 9 . 2}$ \\
\hline Peo\% & 93 & 94 & 95 & 96 & 97 & 98 & 99 & $\mathbf{1 0 0}$ \\
\hline
\end{tabular}


التسيق الرصين لتصميم مُنثبت نظام القدرة ونظام الإثارة باستخدام خوارزمية جينية لتحسين الاستقرار الديناميكي لمحطة الزارة لتوليد القدرة الحرارية في سوريا

\section{رياض المصطفى'، و أنس فتوح'، و وسن هاشّ}

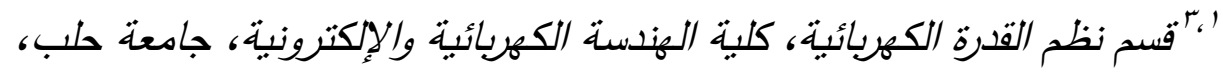

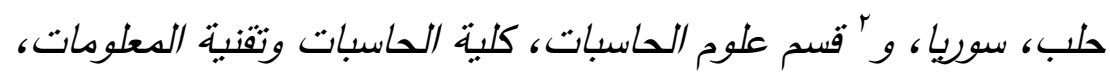

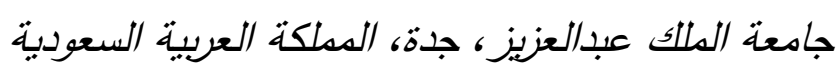

المستخلص. تم في هذه الدراسـة اعتماد صيغة جديدة لـُتبت نظـام

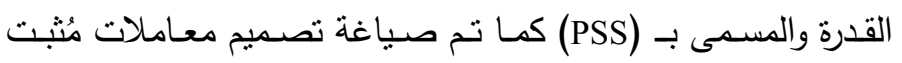

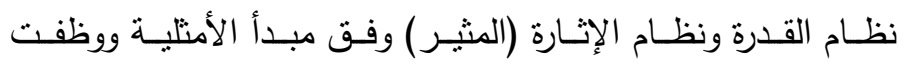

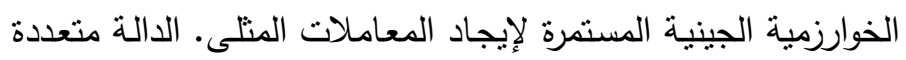

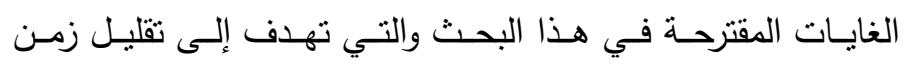

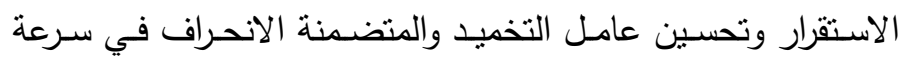
الدوران التذبذبي للمولد أدت إلى تحسين أداء استقرار النظام. تم تتفيذ التصـيم على نمـوذج رياضـي حقيقي وشـامل لمحطـة الزارة لتوليد القدرة الحرارية في سوريا في ظروف نشغيل مختلفة وعطل كبير .

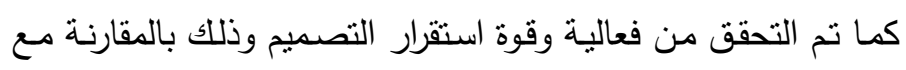
مُثبت نظام القدرة التقليدي.

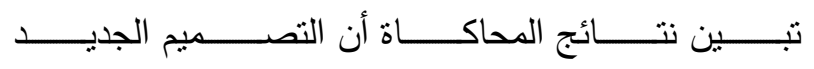
قادر على توفير التخامد الجيد على نطاق (GAPSS + GAExciter)

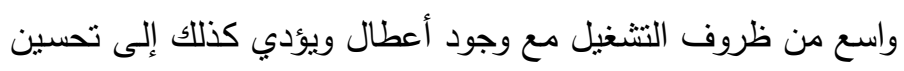

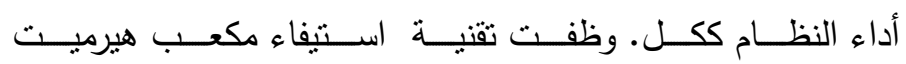


لتحديد منحنى أملس يمر من خلال (cubic Hermite interpolation) مجموعة البيانات التي تم الحصول عليها من الخوارزمية الجينية. ومـن خـلال المقارنـة مـع أداء النظـام الديناميكي عند حدوث عطل كبير مـع نتـائج النمـوذج عندـ اسـتخدام الخوارزميـة الجينيـة تبـين أن النتائج مُشتجعة. 